\title{
On hematological features in adolescents with periodontitis
}

\author{
Rodrigo Lopez • Bruno G. Loos • Vibeke Baelum
}

Received: 29 February 2012 / Accepted: 1 March 2012 /Published online: 16 March 2012

(C) Springer-Verlag 2012

\section{Dear Editor,}

We appreciate the opportunity raised by this letter to the editor to explain in more details some relevant aspects of our study [1].

Mr. Joob and Mr. Wiwanitkit state that “...there are many confounding factors that can cause the periodontal disorders.... Of interest, those factors (such as personnel illness, smoking, drug usage, underlying genetic disorders, etc.) are not well controlled in this work."

In their rather unspecific critique, Mr. Joob and Mr. Wiwanitkit overlooked the fact that confounding is only present in an association if the factor in question is (1) associated with the exposure, (2) associated with the outcome, and (3) it is not an intermediate step in the causal pathway between them [2]. Mr. Joob and Mr. Wiwanitkit do not present any evidence for the alleged confounders listed. However, we accept (and have indeed done so in our study) both smoking and drug usage as potential confounders. However, none of the participants were receiving medications, and the distribution of smoking was nicely balanced between cases of periodontitis and controls as illustrated in Table 1 of

\section{R. Lopez $(\bowtie)$}

Department of Periodontology, Faculty of Health Sciences,

Aarhus University,

Aarhus, Denmark

e-mail: rlopez@odont.au.dk

\section{B. G. Loos}

Section Periodontology and Oral Biochemistry,

Academic Center for Dentistry Amsterdam,

Amsterdam, The Netherlands

V. Baelum

School of Dentistry and Department of Epidemiology,

Faculty of Health Sciences, Aarhus University,

Aarhus, Denmark our article. In addition, the multiple linear regression analyses of the relationship between eosinophil counts/platelet volume and periodontitis case-status were indeed smoking-adjusted, as Mr. Joob and Mr. Wiwanitkit might have seen in the "Materials and methods" section and in Table 3.

Mr. Joob and Mr. Wiwanitkit find that the number of participants is low, and that the use of an unmatched study design "might affect the results." In view of the rather unspecific nature of these comments, we refrain from discussing them further, noting that the size of the study group was evidently sufficient to establish some statistically significant associations.

Finally, Mr. Joob and Mr. Wiwanitkit state that "the quality control of the use of the blood cell analyzer might affect the results." Again, this is a very unspecific critique. The hematology analyzer used in our study was calibrated on a weekly basis, and has repeatedly been reported to possess comparable or better analytical qualities than other methods [3-5].

Sincerely yours,

\section{References}

1. Lopez R, Loos BG, and Baelum V Hematological features in adolescents with periodontitis. Clin Oral Investig [Epub ahead of print]

2. Last JM (2001) A dictionary of epidemiology. 4th edn. Oxford University Press, New York. pp 1-196

3. Albitar M, Dong Q, Saunder D, Lucas L, Kaabi L, Zaldivar E, Thall PF (1999) Evaluation of automated leukocyte differential counts in a cancer center. Lab Hematol 5:10-14

4. Muller TH, Doscher A, Schunter F, Scott CS (1997) Manual and automated methods for the determination of leukocyte counts at extreme low levels: comparative evaluation of Nageotte chamber and the Abbott Cell Dyn 3500 analyser. Transfus Sci 18:505-515

5. Vives-Corrons JL, Besson I, Jou JM, Gutierrez G (1996) Evaluation of the Abbott Cell-DYN 3500 hematology analyzer in university hospital. Am J Clin Pathol 105:553-559 